\title{
Antioxidant, Pancreatic Lipase Inhibitory, and Tyrosinase Inhibitory Activities of Extracts of the Invasive Plant Spartina anglica (Cord-Grass)
}

\author{
Geum Jin Kim ${ }^{1,2}$, Songhee Park ${ }^{1}$, Eonmi Kim ${ }^{1}$, Hyukbean Kwon ${ }^{1}$, Hae-Jin Park ${ }^{3} \mathbb{C}^{\text {, Joo-Won Nam }}{ }^{1}{ }^{\mathbb{D}}$, \\ Seong-Soo Roh ${ }^{4, *(\mathbb{D})}$ and Hyukjae Choi $1,2, * \mathbb{D}$ \\ 1 College of Pharmacy, Yeungnam University, Gyeongsan, Gyeongsangbukdo 38541, Korea; \\ kimgeumjin@naver.com (G.J.K.); psh5959@naver.com (S.P.); minnie60@hanmail.net (E.K.); \\ zero9602@gmail.com (H.K.); jwnam@yu.ac.kr (J.-W.N.) \\ 2 Research Institute of Cell Culture, Yeungnam University, Gyeongsan, Gyeongsangbukdo 38541, Korea \\ 3 Faculty of Herbal Cuisine and Nutrition, Daegu Haany University, Daegu 42158, Korea; hjpark@dhu.ac.kr \\ 4 Department of Herbology, Daegu Haany University, Daegu 42158, Korea \\ * Correspondence: ddede@dhu.ac.kr (S.-S.R.); h5choi@yu.ac.kr (H.C.); Tel.: +82-53-770-2258 (S.-S.R.); \\ +82-53-810-2824 (H.C.)
}

Citation: Kim, G.J.; Park, S.; Kim, E.; Kwon, H.; Park, H.-J.; Nam, J.-W.; Roh, S.-S.; Choi, H. Antioxidant, Pancreatic Lipase Inhibitory, and Tyrosinase Inhibitory Activities of Extracts of the Invasive Plant Spartina anglica (Cord-Grass). Antioxidants 2021, 10, 242. https://doi.org/ 10.3390/antiox10020242

Academic Editor: Vittorio Calabrese Received: 24 December 2020

Accepted: 31 January 2021

Published: 4 February 2021

Publisher's Note: MDPI stays neutral with regard to jurisdictional claims in published maps and institutional affiliations.

Copyright: (c) 2021 by the authors. Licensee MDPI, Basel, Switzerland. This article is an open access article distributed under the terms and conditions of the Creative Commons Attribution (CC BY) license (https:// creativecommons.org/licenses/by/ $4.0 /)$.

\begin{abstract}
Since 2016, the invasive halophyte Spartina anglica has been colonizing mudflats along the western coast of South Korea. In order to minimize costs on S. anglica expansion management and waste-treatment of collected biomass, the potential application of the collected biomass of S. anglica was investigated. Ethanolic extracts and subfractions thereof (hexanes, methylene chloride, ethyl acetate, 1-butanol, and water-soluble) of the aerial and belowground parts of S. anglica showed free radical-scavenging [2,2-diphenyl-1-picrylhydrazyl (DPPH), and 2,2'-azinobis(3-ethylbenzothiazoline-6-sulfonic acid) (ABTS)], tyrosinase inhibitory, and pancreatic lipase inhibitory activities. An ethyl acetate fraction derived from aerial parts (EA-a) showed the most potent radical-scavenging and pancreatic lipase inhibitory activities, whereas tyrosinase inhibition was mainly observed in the methylene chloride soluble fractions (MC-bg) and other lipophilic fractions (ethyl acetate and hexanes layers) obtained from belowground parts. The major EA-a compound isolated and identified was 1,3-di-O-trans-feruloyl quinic acid (1) based on spectroscopic analysis, whereas the two major MC-bg compounds were identified as $p$-hydroxybenzaldehyde (2) and N-trans-feruloyltyramine (3). Compounds 1 and 3 scavenged both DPPH and ABTS radicals, whereas $\mathbf{1}$ and $\mathbf{2}$ inhibited pancreatic lipase activity. These results indicate that extracts and fractions of $S$. anglica have antioxidant, anti-obesity, and whitening properties with potential pharmaceutical, cosmeceutical, and functional food applications.
\end{abstract}

Keywords: Spartina anglica; invasive plant; antioxidant activity; tyrosinase inhibition; pancreatic lipase inhibition

\section{Introduction}

Spartina anglica C. E. Hubb (Poaceae) is a herbaceous perennial plant, commonly referred to as "cord-grass", that inhabits coastal areas of southern England and western France [1]. Given its dense roots that can tightly bind coastal mud, S. anglica was initially planted with a view toward protecting coastal areas against erosion and has subsequently been used extensively in the reclamation of tidal flats [2]. However, with the emerging awareness of the ecological importance of mudflats, the detrimental effects of S. anglica on mudflat ecosystems have become increasingly apparent. In areas colonized by S. anglica, the native vegetation is gradually displaced, thereby transforming mudflat habitats into a comparatively ecologically poor monoculture [3]. In addition, the invasion of S. anglica disrupts the habitats of mud-inhabiting invertebrates, migratory birds, and breeding fish, while contributing to biochemical modifications, such as hazardous heavy metal 
pollution [4-6]. Spartina anglica is accordingly currently classified as an invasive plant with the potential to devastate coastal mudflats [7]. Since the occurrence of S. anglica was first reported in the southern parts of Ganghwa Island, South Korea, in 2012, the area colonized by $S$. anglica has rapidly expanded, and the plant has been designated as an "unintroduced species" by the Korean government [8]. Although management to prevent the invasive expansion of S. anglica in coastal areas of Korea is considered a high priority, it is labor- and time-intensive. Furthermore, the collected biomass of S. anglica is a biological waste that incurs additional waste-treatment costs. To minimize these costs, we attempted to discover a potential use for the collected biomass of S. anglica as a source of bioactive compounds for the development of biomedicines and cosmetics.

Reactive oxygen species (ROS) are a byproduct of cell metabolism and are involved in biological processes such as apoptosis and protection of cells against pathogens [9]. However, owing to their high oxidizing property, ROS can damage tissues and organs and are associated with the aging process as well as diverse human diseases such as cancers, atherosclerosis, and diabetes [9]. Natural antioxidants are scavengers of ROS and protect tissues and organs from ROS-derived oxidative stress. Therefore, several industrial markets exist for natural antioxidants as ingredients of functional foods and cosmetics [10]. Tyrosinase is an enzyme related to the hyperpigmentation of human skin, and its inhibitor can be used as a bioactive ingredient in skin-whitening cosmetics [11,12]. Pancreatic lipase hydrolyzes dietary fat into free fatty acids and monoglycerides, and its inhibitor (orlistat) is widely used as an anti-obesity drug in clinical settings [11].

Previous chemical investigations of $S$. anglica have revealed the presence of dimethylsulfoniumpropanoic acid, proline, glycine betaine, and polysaccharides [13-16]. In addition, algicidal flavonols, such as isorhamnetin-3-O-sophoroside-7-O-rhamnoside and syringetin-3-O-galactoside, and antioxidant flavonols, such as 5,4'-dihydroxy-3'-methoxyflavonol-3-O-glucosyl-( $1 \rightarrow 6)$-glucosyl-7-O-rhamnoside, 5-hydroxy-3'-methoxy-flavonol3-O-glucosyl-( $(1 \rightarrow 6)$-glucosyl-7-O-rhamnoside, and 5-hydroxy-3', $4^{\prime}$-dimethoxy-flavonol3 -O-glucosyl- $(1 \rightarrow 6)$-glucosyl-7-O-rhamnoside, have been reported [17,18]. Apart from identifying these constituents, the biological activities of extracts of S. anglica, particularly the antioxidant activities of compounds derived from different plant parts, are yet to be investigated. In this study, we obtained extracts and fractions from the aerial and belowground parts of $S$. anglica and evaluated these for bioactivities with potential industrial applications, namely, free radical (2,2-diphenyl-1-picrylhydrazyl (DPPH) and 2,2'-azino-bis(3-ethylbenzothiazoline-6-sulphonic acid) (ABTS)) scavenging activities and the inhibition of pancreatic lipase and tyrosinase.

\section{Materials and Methods}

\subsection{Chemicals and Reagents}

All organic solvents used for extraction, liquid-liquid extraction, and normal phase (NP) vacuum liquid chromatography (VLC) (ethanol, hexanes, methylene chloride, ethyl acetate, and 1-butanol) were of extra-pure grade and obtained from Duksan Chemical Co. (Ansan, South Korea). Acetonitrile (high-performance liquid chromatography (HPLC) and liquid chromatography-mass spectrometry grade), methanol (HPLC grade), and formic acid (liquid chromatography-mass spectrometry grade) were obtained from Fisher Chemical (Pittsburgh, PA, USA). Deionized water was collected from a Direct-Q 5 UV water purification system (18 $\mathrm{M} \Omega \mathrm{cm}^{-1}$; Merck KGaA, Darmstadt, Germany). The internal calibrant (methyl 3,5-dinitrobenzoate) for quantitative ${ }^{1} \mathrm{H}$ nuclear magnetic resonance, 2,2-diphenyl-1-picrylhydrazyl (DPPH), 2,2'-azino-bis(3-ethylbenzothiazoline-6-sulfonic acid) (ABTS), potassium persulfate, Folin-Ciocalteu's phenol reagent, gallic acid, tyrosinase, L-3,4-dihydroxyphenylalanine (L-DOPA), kojic acid, porcine pancreatic lipase (Type II), orlistat, 4-morpholinepropanesulfonic acid (MOPS), ethylenediaminetetraacetic acid (EDTA), $p$-nitrophenyl butyrate ( $p$-NPB), dimethylformamide (DMF), Tris(hydroxymethyl) aminomethane hydrochloride (Tris- $\mathrm{HCl}$ ), and absolute ethanol were purchased from Sigma Aldrich Co. (St. Louis, MO, USA). Sodium carbonate was obtained from Daejung Chemi- 
cals \& Metals Co., Ltd. (Siheung, Korea). Dimethyl sulfoxide (DMSO) was purchased from PanReac Applichem (Darmstadt, Germany). L-Ascorbic acid was purchased from Alfa Aesar (Lancashire, UK).

\subsection{Plant Materials}

In July 2016, specimens of S. anglica ( $30 \mathrm{~kg}$ ) were collected from a mudflat on Ganghwa Island, Incheon, South Korea $\left(126^{\circ} 27^{\prime} 18^{\prime \prime} \mathrm{E}, 37^{\circ} 35^{\prime} 36^{\prime \prime} \mathrm{N}\right)$ and were identified by one of the authors (H.C.). A voucher specimen (16K009) has been deposited at the College of Pharmacy, Yeungnam University, Gyeongsan, Korea.

\subsection{Extraction and Fractionation}

The collected plant material was washed and dried at $24{ }^{\circ} \mathrm{C}$ under dark conditions for 1 week, and the dried plants were subsequently separated into aerial and belowground parts. Each part (dry wt. $10 \mathrm{~kg}$ ) was extracted three times with $80 \% \mathrm{EtOH}$ and dried under reduced pressure, thereby yielding extracts of the aerial (EtOH-a, $3.3 \mathrm{~kg}$ ) and belowground parts (EtOH-bg, $554 \mathrm{~g}$ ) parts. These crude extracts were further fractionated using liquidliquid extraction. A small portion of the EtOH-a extract $(1.8 \mathrm{~g})$ was re-suspended in $250 \mathrm{~mL}$ of deionized water and extracted three times with $250 \mathrm{~mL}$ of hexanes. The combined hexanes-soluble layers of aerial part extracts were evaporated to give a hexanes-soluble fraction (Hex-a, $102 \mathrm{mg}$ ). The remaining extract of the aerial parts was extracted three times with methylene chloride and the combined organic layers were dried to give a methylene chloride-soluble fraction of the aerial parts (MC-a, $92 \mathrm{mg}$ ). The residual aqueous layer was extracted three times with ethyl acetate and the resulting aqueous layer was further extracted three times with water-saturated 1-butanol. The ethyl acetate, 1-butanol, and aqueous layers were independently lyophilized to give the fractions EA-a (111 mg), BuOH-a (531 mg), and $\mathrm{H}_{2} \mathrm{O}-\mathrm{a}(1015 \mathrm{mg})$, respectively. Using the same procedures, a small portion $(11.0 \mathrm{~g})$ of the EtOH-bg extract was fractionated to yield the following five sub-fractions: Hex-bg (234 mg), MC-bg (271 mg), EA-bg (196 mg), BuOH-bg (241 mg), and $\mathrm{H}_{2} \mathrm{O}-\mathrm{bg}$ (9400 mg).

\subsection{DPPH Free Radical-Scavenging Activity}

DPPH free radical-scavenging properties were evaluated using a previously reported method [19]. Test sample (an extract, a fraction or a compound) in $100 \mu \mathrm{L}$ of dimethyl sulfoxide (DMSO) (blank: $100 \mu \mathrm{L}$ of DMSO solution) was added to $100 \mu \mathrm{L}$ of an ethanolic solution of DPPH $(60 \mu \mathrm{M})$ in the wells of a 96-well microplate. Ascorbic acid (standard sample) and each sample were prepared at $100 \mu \mathrm{g} / \mathrm{mL}$. After the sample and the reagents had been mixed gently and incubated for $30 \mathrm{~min}$ at room temperature, the absorbance $(A)$ at $540 \mathrm{~nm}$ was evaluated using a microplate reader (Model Infinite M200 PRO; Tecan, Austria). The free radical-scavenging activity was calculated as a percentage using the equation

$\mathrm{DPPH}$ free radical-scavenging activity $(\%)=\left[1-\left(A_{\text {sample }} / A_{\text {blank }}\right)\right] \times 100$.

\subsection{ABTS Assay}

ABTS radical-scavenging activity was measured using a modified method of Re et al. [20]. The ABTS stock solution was diluted in water to a concentration of $7.4 \mathrm{mM}$. The ABTS radical was produced by mixing ABTS stock solution with $2.45 \mathrm{mM}$ potassium persulfate and incubating in dark for $12 \mathrm{~h}$ at room temperature. The ABTS solution was diluted with ethanol to obtain an absorbance $\left(A_{\text {blank }}\right)$ of $0.70 \pm 0.02$ at $415 \mathrm{~nm}$. After adding $95 \mu \mathrm{L}$ of diluted ABTS solution to $5 \mu \mathrm{L}$ of the sample, the mixture was incubated at room temperature for $15 \mathrm{~min}$ in dark. The absorbance $\left(A_{\text {sample }}\right)$ at $415 \mathrm{~nm}$ was measured using a microplate reader (Model Infinite M200 PRO; Tecan, Austria). The blank was prepared using the same procedure with deionized water instead of the sample. The ABTS radical scavenging activity was calculated as a percentage using the Equation (2)

$$
\text { ABTS radical scavenging activity }(\%)=\left[1-\left(A_{\text {sample }} / A_{\text {blank }}\right)\right] \times 100
$$




\subsection{Tyrosinase Inhibition Assay}

The tyrosinase inhibition assay was performed using a modification of the method reported by Nerya et al. [21]. A portion of a sample $(20 \mu \mathrm{L})$ in DMSO $(100 \mu \mathrm{g} / \mathrm{mL})$ was mixed with $50 \mu \mathrm{L}$ of $0.1 \mathrm{M}$ potassium phosphate buffer ( $\mathrm{pH} 6.8$ ), to which was added $30 \mu \mathrm{L}$ of $33 \mathrm{unit} / \mathrm{mL}$ tyrosinase and $100 \mu \mathrm{L}$ of $12 \mathrm{mM} \mathrm{L}-3,4$-dihydroxyphenylalanine (L-DOPA). The solution was mixed gently and the initial absorbance $\left(A_{\text {initial }}\right)$ was recorded at $492 \mathrm{~nm}$ using a microplate reader. The reaction mixture was then incubated at $37^{\circ} \mathrm{C}$ for $4 \mathrm{~min}$ and thereafter the final absorbance $\left(A_{\text {final }}\right)$ was measured at $492 \mathrm{~nm}$. Kojic acid was used as the reference drug. The tyrosinase inhibition activity was calculated as a percentage using the Equation (3)

$$
\text { Tyrosinase inhibition activity }(\%)=\left[1-\left(A_{\text {final }} / A_{\text {initial }}\right)\right] \times 100
$$

\subsection{Pancreatic Lipase Inhibition Assay}

Pancreatic lipase activity was measured using the method previously reported by Kim et al. [22]. An enzyme buffer was prepared by the addition of $6 \mu \mathrm{L}$ of porcine pancreatic lipase solution (Sigma-Aldrich, St. Louis, MO, USA) in a buffer (10 mM morpholinepropanesulfonic acid and $1 \mathrm{mM}$ EDTA, $\mathrm{pH}$ 6.8) to Tris buffer $(169 \mu \mathrm{L}, 100 \mathrm{mM}$ Tris-HCl, and $\left.5 \mathrm{mM} \mathrm{CaCl}_{2}, \mathrm{pH} 7.0\right)$. Aliquots $(20 \mu \mathrm{L})$ of each sample and orlistat at $100 \mu \mathrm{g} / \mathrm{mL}$ were then mixed with $175 \mu \mathrm{L}$ enzyme buffer and incubated for 15 min at $37^{\circ} \mathrm{C}$ with $5 \mu \mathrm{L}$ of the substrate solution (10 $\mathrm{mM} p$-NPB ( $p$-nitrophenyl butyrate) in dimethylformamide). The enzymatic reaction mixtures were incubated at $37^{\circ} \mathrm{C}$ for $35 \mathrm{~min}$. Pancreatic lipase activity was determined by measuring the hydrolysis of $p$-NPB to $p$-nitrophenol, with absorption being recorded at $405 \mathrm{~nm}$ using a microplate reader (Model Infinite M200 PRO; Tecan, Austria). Inhibition of lipase activity was expressed in terms of the percentage reduction in absorbance when porcine pancreatic lipase was incubated with the test compounds, and calculated using the following Equation (4)

$$
\text { Inhibition }(\%)=100-[(B-b) /(A-a) \times 100]
$$

where $A$ is the lipase activity without inhibitor, $a$ is the negative control without inhibitor, $B$ is the lipase activity with inhibitor, and $b$ is the negative control with inhibitor. The results are expressed as an average $(n=4)$.

\subsection{Measurement of Total Phenol Contents}

Total phenol contents were measured using the Folin-Denis method [23]. Samples $(20 \mu \mathrm{L})$ were mixed with DMSO $(1.58 \mathrm{~mL})$ and Folin-Ciocalteu's phenol reagent $(100 \mu \mathrm{L})$, and incubated at room temperature for $1 \mathrm{~min}$, followed by the addition of sodium carbonate solution $(20 \% \mathrm{v} / \mathrm{v}, 300 \mu \mathrm{L})$. After incubating the mixture at $20^{\circ} \mathrm{C}$ for $2 \mathrm{~h}$, the absorbance was measured at $765 \mathrm{~nm}$ using a microplate reader (Model Infinite M200 PRO; Tecan, Austria). Gallic acid was used as the reference material.

\subsection{Chemical Profiles of the Biologically Active Fractions (EA-a and MC-bg)}

Chromatographic profiling of the most active fractions, EA-a and MC-bg, was performed using an Agilent 1260 Infinity high-performance liquid chromatograph equipped with a reversed-phase C18 column (Phenomenex Luna $3 \mu$ C18(2) $100 \AA, 4.6 \times 150 \mathrm{~mm}$ ). The solvent system used was as follows: solvent A ( $95 \%$ deionized water, $5 \%$ acetonitrile with $0.05 \%$ formic acid), solvent B (100\% acetonitrile with $0.05 \%$ formic acid); A:B $=95: 5 \rightarrow 95: 5$ $(2 \mathrm{~min}) \rightarrow 0: 100(12.5 \mathrm{~min}) \rightarrow$ 0:100 $(15 \mathrm{~min}) \rightarrow$ 95:5 $(16 \mathrm{~min}) \rightarrow$ 95:5 (19 $\mathrm{min})$ at a flow rate of $0.7 \mathrm{~mL} / \mathrm{min}$. Compounds were detected using diode array detector (DAD: Agilent 1260 Infinity DAD; Agilent Technologies, Santa Clara, CA, USA) and electrospray ionizationmass spectrometry detector (ESI MS: Agilent 6120 single-quadrupole mass spectrometer; Agilent Technologies, Santa Clara, CA, USA). 


\subsection{Isolation of Major Compounds from the Bioactive Fractions (EA-a and MC-bg)}

EA-a $(6.6 \mathrm{~g})$ was subjected to stepped-gradient NP VLC to yield 14 fractions (EA-a-A$\mathrm{N})$. Fractions $\mathrm{K}-\mathrm{M}$, eluted with $60-30 \%$ ethyl acetate in methanol, were found to include compound 1. After combining the fractions K-M, EA-a-KLM (935 mg) was subjected to normal phase medium-pressure liquid chromatography for the preparation of nine subfractions (EA-a-KLM-1-9). Among these subfractions, EA-a-KLM-6 (476.7 mg), eluted with 70\% methylene chloride in $30 \%$ methanol, was injected into a preparative high-performance liquid chromatograph equipped with a reversed-phase C18 column (Phenomenex Luna C18; $100 \AA, 22.5 \times 250 \mathrm{~mm}$ ). The system used comprised solvent A (95\% deionized water, $5 \%$ acetonitrile with $0.05 \%$ formic acid) and solvent $\mathrm{B}(100 \%$ acetonitrile $)(\mathrm{A}: \mathrm{B}=82: 18)$ at a flow rate of $6.0 \mathrm{~mL} / \mathrm{min}$, with detection at 210 and $254 \mathrm{~nm}$. Compound $\mathbf{1}(55.2 \mathrm{mg}$, retention time $38.849 \mathrm{~min}$ ) was accordingly obtained, the structure of which was determined by spectroscopic analysis.

MC-bg (271.1 mg) was subjected to NP VLC, which yielded seven fractions (MC-bgA-G). A fraction (MC-bg-D, $56.9 \mathrm{mg}$ ) containing compounds $\mathbf{2}$ and $\mathbf{3}$ was subjected to preparative HPLC using a reversed-phase C18 column (Phenomenex Luna C18, $100 \AA$, $22.5 \times 250 \mathrm{~mm})$. The solvent system used comprised solvent A (100\% deionized water) and solvent $\mathrm{B}(100 \%$ acetonitrile $)(\mathrm{A}: \mathrm{B}=74: 26)$ at a flow rate of $6.0 \mathrm{~mL} / \mathrm{min}$, with detection at 210 and $254 \mathrm{~nm}$. The structures of compound $2(0.6 \mathrm{mg}$, retention time $13.759 \mathrm{~min})$ and 3 ( $3.2 \mathrm{mg}$, retention time $35.612 \mathrm{~min}$ ) thus obtained were confirmed by spectroscopic analyses.

\subsection{Quantitative Analysis of the Major Compounds in EA-a and MC-bg}

The weight percentage of compound $\mathbf{1}$ in EA-a and that of compounds $\mathbf{2}$ and $\mathbf{3}$ in MC-bg were calculated using quantitative ${ }^{1} \mathrm{H}$ nuclear magnetic resonance (qHNMR) with an internal calibrant. EA-a and MC-bg were thoroughly dried in a vacuum chamber and three samples of precisely weighed $(10.0 \mathrm{mg})$ EA-a and MC-bg were prepared, each of which was dissolved in $600 \mu \mathrm{L}$ of DMSO- $d_{6}$ (99.8\% D; Euriso-Top, Saclay, France). Methyl 3,5-dinitrobenzoate (precisely weighed: $3.4 \mathrm{mg}$ ), dissolved in DMSO- $d_{6}$ to give a $5.7 \mathrm{mg} / \mathrm{mL}$ solution, was used as an internal calibrant. Aliquots $(20 \mu \mathrm{L})$ of the internal calibrant were added to each prepared EA-a and MC-bg sample solution, and $600 \mu \mathrm{L}$ of each sample was transferred to a $5 \mathrm{~mm}$ NMR tube. ${ }^{1} \mathrm{H}$ NMR spectra were acquired at $25^{\circ} \mathrm{C}$ in a 600-MHz Fourier Transform Nuclear Magnetic Resonance device (VNS600; Agilent Technologies, Santa Clara, CA, USA) at the Core Research Support Center for Natural Products and Medical Materials (CRCNM) in Yeungnam University with the following parameters: a calibrated $90^{\circ}$ pulse, 64 scans, and a 60 -s relaxation delay (D1). Each ${ }^{1} \mathrm{H}$ NMR spectrum was manually processed by phasing, baseline correction with a fifth-order polynomial function, and referencing with the residual solvent signal at $2.51 \mathrm{ppm}$, using Mnova 9.0 (Mestrelab Research SL, Santiago de Compostela, Spain). Further processing was performed by apodization $(\mathrm{LB}=-0.3 \mathrm{~Hz}, \mathrm{GF}=0.05)$ and zero filling ( $256 \mathrm{~K}$ data points). For the quantitative analysis of compounds $1-3$, a doublet of the $\mathrm{sp} 2$ proton at $6.42 \mathrm{ppm}$ of 1 , a singlet of an aldehyde proton at $9.78 \mathrm{ppm}$ and a doublet of ortho-coupled $\mathrm{sp} 2$ protons at $7.75 \mathrm{ppm}$ of 2 , and a triplet of the sp3 proton at $2.64 \mathrm{ppm}$ of 3 , as well as a doublet of meta-coupled protons at $8.91 \mathrm{ppm}$ of the internal calibrant were used. The integration value of each peak was obtained after peak deconvolution to give precise measurement without interference of peak overlap.

\subsection{Statistical Analysis}

All data are presented as the mean \pm standard deviation (SD) and are representative of at least three independent experiments. Statistical comparisons between groups were made using Sigma plot 9.0 statistical software (Systat Software Inc, San Jose, CA, USA). 


\section{Results}

\subsection{Biological Activities of the Extracts and Fractions of S. anglica}

The antioxidant potentials of $S$. anglica extracts were evaluated based on the scavenging of DPPH free radicals and ABTS radicals. Both the EtOH-a and EtOH-bg extracts $(100 \mu \mathrm{g} / \mathrm{mL})$ of $S$. anglica were found to possess radical-scavenging activities, as shown in Table 1. Compared with EtOH-bg, the EtOH-a extract showed slightly more potent radical-scavenging activities for both DPPH (18.5\% inhibition) and ABTS (39.4\% inhibition) radicals. We found that the fractions EA-a, BuOH-a, and MC-a (100 $\mu \mathrm{g} / \mathrm{mL}$ each) also scavenged DPPH $(55.9 \%, 41.7 \%$, and $38.4 \%$, respectively) and ABTS $(68.8 \%, 47.3 \%$, and $58.8 \%$, respectively) radicals. Among the fractions derived from an extract of the belowground parts of S. anglica, MC-bg and EA-bg also showed antioxidant activities against DPPH (38.1\% and $28.6 \%$ inhibition, respectively) and ABTS (50.1\% and $44.2 \%$ inhibition, respectively) radicals.

Table 1. Bioactivities of the extracts and fractions of Spartina anglica at $100 \mu \mathrm{g} / \mathrm{mL}$.

\begin{tabular}{ccccc}
\hline Sample & $\begin{array}{c}\text { Radical-Scavenging } \\
\text { Activity Against } \\
\text { DPPH (\%) }\end{array}$ & $\begin{array}{c}\text { Radical-Scavenging } \\
\text { Activity Against } \\
\text { ABTS (\%) }\end{array}$ & $\begin{array}{c}\text { Inhibition of L-DOPA } \\
\text { Oxidation (\%) }\end{array}$ & $\begin{array}{c}\text { Inhibition of } \\
\text { Pancreatic Lipase (\%) }\end{array}$ \\
\hline Control & $98.5 \pm 0.2^{1}$ & $99.5 \pm 0.3^{1}$ & $98.6 \pm 0.4^{2}$ & $67.8 \pm 0.0^{3}$ \\
EtOH-a & $18.5 \pm 4.4$ & $39.4 \pm 0.4$ & $30.4 \pm 1.0$ & $47.7 \pm 0.4$ \\
Hex-a & $2.0 \pm 0.6$ & $5.9 \pm 0.5$ & $36.8 \pm 0.6$ & $36.6 \pm 0.3$ \\
MC-a & $38.4 \pm 2.7$ & $58.8 \pm 0.8$ & $38.2 \pm 1.5$ & $38.4 \pm 0.5$ \\
EA-a & $55.9 \pm 0.6$ & $68.8 \pm 0.3$ & $43.9 \pm 0.5$ & $51.2 \pm 0.5$ \\
BuOH-a & $41.7 \pm 1.4$ & $47.3 \pm 0.3$ & $42.5 \pm 1.2$ & $32.7 \pm 0.7$ \\
H ${ }_{2} \mathrm{O}-\mathrm{a}$ & $8.3 \pm 1.8$ & $11.8 \pm 0.4$ & $44.0 \pm 1.6$ & $22.7 \pm 0.8$ \\
EtOH-bg & $11.1 \pm 1.4$ & $19.6 \pm 0.5$ & $29.5 \pm 0.5$ & $49.5 \pm 0.5$ \\
Hex-bg & $6.7 \pm 1.2$ & $10.2 \pm 0.7$ & $85.9 \pm 0.3$ & $46.0 \pm 1.2$ \\
MC-bg & $38.1 \pm 1.5$ & $50.1 \pm 0.4$ & $69.4 \pm 0.8$ & $33.3 \pm 0.8$ \\
EA-bg & $28.6 \pm 1.1$ & $44.2 \pm 1.2$ & $43.4 \pm 0.6$ & $38.6 \pm 0.9$ \\
BuH-bg & $5.0 \pm 6.2$ & $12.2 \pm 0.2$ & $41.6 \pm 0.3$ & $0.0 \pm 0.7$ \\
$\mathrm{H}_{2} \mathrm{O}-\mathrm{bg}$ & $-0.4 \pm 0.4$ & $3.0 \pm 0.7$ & & $26.4 \pm 0.6$ \\
\hline
\end{tabular}

Extracts and fractions derived from the aerial and belowground parts of S. anglica were also evaluated for the inhibition of tyrosinase, which is a key enzyme in melanin biosynthesis via the oxidation of L-DOPA. We found that the fractions EtOH-a and EtOH-bg $(100 \mu \mathrm{g} / \mathrm{mL})$ inhibited the tyrosinase-induced oxidation of L-DOPA by $30.4 \%$ and $29.5 \%$, respectively. Furthermore, whereas EA-a showed slightly more potent activity in the radical scavenging assay, MC-bg, EA-bg, and Hex-bg showed more potent tyrosinase inhibition activities (85.0\%, 69.4\%, and $67.9 \%$ inhibition, respectively) than those did fractions derived from of aerial parts, as shown in Table 1.

With respect to determining anti-obesity potentials, we also examined the inhibitory effects of extracts and fractions on pancreatic lipase activity (Table 1). Both EtOH-a and EtOH-bg $(100 \mu \mathrm{g} / \mathrm{mL})$ were found to inhibit pancreatic lipase activities $(47.7 \%$ and $49.5 \%$, respectively), whereas among the different fractions, EA-a showed the most potent inhibitory activity $(51.2 \%$ inhibition at $100 \mu \mathrm{g} / \mathrm{mL})$.

The activities of phytochemical antioxidants tend to be attributed primarily to phenols, and thus we also determined the total phenol contents of the examined extracts and fractions to assess the contribution of phenolic compounds to the antioxidant activities of the samples as shown in Table 2. Among the different fractions, EA-a was found to have the highest phenolic content $(155.28 \mathrm{mg} / \mathrm{g})$, with fractions EA-bg, MC-bg and MC-a also containing notable levels of phenolic compounds at concentrations of 105.62, 68.26, and $55.18 \mathrm{mg} / \mathrm{g}$, respectively. 
Table 2. Measurement of total phenol contents of the extracts and fractions of Spartina anglica.

\begin{tabular}{cc}
\hline Sample & Total Phenols $\mathbf{( m g / g )} \mathbf{~}^{\mathbf{1}}$ \\
\hline EtOH-a & $24.91 \pm 0.11$ \\
Hex-a & $15.60 \pm 0.14$ \\
MC-a & $55.18 \pm 0.13$ \\
EA-a & $155.28 \pm 0.30$ \\
BuOH-a & $33.03 \pm 0.13$ \\
$\mathrm{H}_{2} \mathrm{O}-\mathrm{a}$ & $24.94 \pm 0.10$ \\
EtOH-bg & $19.56 \pm 0.06$ \\
Hex-bg & $15.12 \pm 0.05$ \\
MC-bg & $68.26 \pm 0.10$ \\
EA-bg & $105.62 \pm 0.36$ \\
BuOH-bg & $13.87 \pm 0.07$ \\
$\mathrm{H}_{2} \mathrm{O}-\mathrm{bg}$ & $11.69 \pm 0.08$ \\
\hline
\end{tabular}

${ }^{1}$ Coefficient of variation $(\mathrm{CV})$ value is less than 1.0.

Two bioactive fractions EA-a and MC-bg were selectively analyzed by LC-ESI-MS and compared with an in-house UV spectra library (Figures S1 and S2). Compound 1 was observed as a major component in the HPLC profile (210 and $254 \mathrm{~nm}$ ) of EA-a, whereas compounds 2 and 3 were found to be the two major components of MC-bg (210 and $254 \mathrm{~nm})$.

\subsection{Structural Determination of the Major Compounds of Bioactive Fractions}

Compound 1 was isolated based on preparative reverse-phase HPLC, and its chemical structure was identified from spectroscopic analyses of 1D and 2D NMR data (Table 3 and Figure S3) using MS data as shown in Figure 1. The ${ }^{1} \mathrm{H}$ NMR spectrum of 1 exhibited four vinyl proton resonances at $7.54\left(1 \mathrm{H}, \mathrm{d}, J=15.9, \mathrm{H}-7^{\prime \prime}\right), 7.53\left(1 \mathrm{H}, \mathrm{d}, J=15.9, \mathrm{H}-7^{\prime}\right), 6.26(1 \mathrm{H}$, $\left.\mathrm{d}, J=15.9, \mathrm{H}-8^{\prime}\right)$, and $6.16\left(1 \mathrm{H}, \mathrm{d}, J=15.9, \mathrm{H}-8^{\prime \prime}\right)$. The geometries of two double bonds were determined as trans by comparison of the coupling constants. The proton resonances at $6.93\left(1 \mathrm{H}, \mathrm{d}, J=1.9, \mathrm{H}-2^{\prime}\right), 6.88\left(1 \mathrm{H}, \mathrm{dd}, J=8.2,1.9, \mathrm{H}-6^{\prime \prime}\right), 6.83\left(1 \mathrm{H}, \mathrm{d}, J=1.9, \mathrm{H}-2^{\prime \prime}\right), 6.75$ $\left(1 \mathrm{H}, \mathrm{dd}, J=8.2,1.9, \mathrm{H}-6^{\prime}\right), 6.67\left(1 \mathrm{H}, \mathrm{d}, J=8.2, \mathrm{H}-5^{\prime \prime}\right)$, and $6.57\left(1 \mathrm{H}, \mathrm{d}, J=8.1, \mathrm{H}-5^{\prime}\right)$ indicated two sets of 1,3,4-trisubstituted benzene rings. The characteristic proton signals at $5.36(1 \mathrm{H}$, $\mathrm{dt}, J=3.6,3.2, \mathrm{H}-3), 4.28(1 \mathrm{H}, \mathrm{ddd}, J=11.3,9.6,4.5, \mathrm{H}-5), 3.64(1 \mathrm{H}, \mathrm{dd}, J=9.6,3.6, \mathrm{H}-4)$, $2.97\left(1 \mathrm{H}, \mathrm{dt}, J=16.2,3.2, \mathrm{H}-2_{\mathrm{eq}}\right), 2.54\left(1 \mathrm{H}, \mathrm{ddd}, J=13.6,4.5,3.2, \mathrm{H}-6_{\mathrm{eq}}\right), 2.31(1 \mathrm{H}, \mathrm{dd}$, $\left.J=16.2,3.2, \mathrm{H}-2_{\mathrm{ax}}\right)$, and $1.84\left(1 \mathrm{H}, \mathrm{dd}, J=13.6,11.3, \mathrm{H}-6_{\mathrm{ax}}\right)$ were assigned as a quinic acid moiety based on their multiplicities and splitting patterns [24]. The small coupling constant between $\delta_{\mathrm{H}} 2.97\left(1 \mathrm{H}, \mathrm{dt}, J=16.2,3.2, \mathrm{H}-2_{\mathrm{eq}}\right)$ and $2.54\left(1 \mathrm{H}, \mathrm{ddd}, J=13.6,4.5,3.2, \mathrm{H}-6_{\mathrm{eq}}\right)$ was revealed as long-range coupling through 1,3-diequatorial interaction (W-coupling) and $\mathrm{H}-2_{\mathrm{eq}}$ and $\mathrm{H}-6_{\mathrm{eq}}$ were both indicated to be equatorial. This corresponds to the ${ }^{1} \mathrm{H}-{ }^{1} \mathrm{H}$ coupling constants of quinic acid rather than that of epi-quinic acid. On the basis of these observations, the structure of $\mathbf{1}$ was predicted to be a quinic acid derivative attached to two phenyl propanoids.

The additional ${ }^{13} \mathrm{C}$ NMR signals for $C-1\left(\delta_{C} 81.12\right)$ and $C-7\left(\delta_{C} 174.58\right)$ were assigned by heteronuclear multiple bond correlation (HMBC) from H-2, 3, 6 to C-1 and H-2, 6 to $\mathrm{C}-7$, respectively. The HMBC correlations from 3'-O-Me to C-3 and from 3'-O-Me to C-3' indicated that the two phenyl propanoids are both ferulate. The connection of one feruloyl unit was determined by HMBC correlation from H-3 to C-9". The position of the other feruloyl group was confirmed by the characteristic downfield chemical shift at $\delta_{C} 81.12$ (C-1). On the basis of these observations, the planar structure of $\mathbf{1}$ was confirmed as 1,3-diO-trans-feruloyl quinic acid [24]. The specific rotation of $\mathbf{1}$ was measured as -9.7 , which corresponds to the specific rotation of (-)-quinic acid rather than that of (+)-quinic acid. Therefore, we confirmed the identity of compound 1 as 1,3-di-O-trans-feruloyl-(-)-quinic acid with an absolute configuration of $1 R, 3 R, 4 S, 5 R(1 \alpha, 3 \alpha, 4 \alpha, 5 \beta)$. 
Table 3. NMR data of 1,3-di-O-trans-feruloyl-(-)-quinic acid (1) in $\mathrm{CD}_{3} \mathrm{OD}$.

\begin{tabular}{|c|c|c|}
\hline Unit and Position & $\delta_{C}(62.5 \mathrm{MHz})$ & $\delta_{\mathrm{H}}(600 \mathrm{MHz})$ \\
\hline \multicolumn{3}{|l|}{ (-)-Quinic acid } \\
\hline 1 & $81.12^{1}, \mathrm{C}$ & \\
\hline 2 & $32.74, \mathrm{CH}_{2}$ & $\begin{array}{l}2.31\left(1 \mathrm{H}, \mathrm{dd}, J=16.2,3.2, \mathrm{H}-2_{\mathrm{ax}}\right) \\
2.97\left(1 \mathrm{H}, \mathrm{dt}, J=16.2,3.2, \mathrm{H}-2_{\mathrm{eq}}\right)\end{array}$ \\
\hline 3 & $73.21, \mathrm{CH}$ & $5.36(1 \mathrm{H}, \mathrm{dt}, J=3.6,3.2)$ \\
\hline 4 & $75.31, \mathrm{CH}$ & $3.64(1 \mathrm{H}, \mathrm{dd}, J=9.6,3.6)$ \\
\hline 5 & $67.80, \mathrm{CH}$ & $4.28(1 \mathrm{H}, \mathrm{ddd}, J=11.3,9.6,4.5)$ \\
\hline 6 & $41.46, \mathrm{CH}_{2}$ & $\begin{array}{c}1.84\left(1 \mathrm{H}, \mathrm{dd}, J=13.6,11.3, \mathrm{H}-6_{\mathrm{ax}}\right) \\
2.54\left(1 \mathrm{H}, \mathrm{ddd}, J=13.6,4.5,3.2, \mathrm{H}-6_{\mathrm{eq}}\right)\end{array}$ \\
\hline 7 & $174.58^{1}, \mathrm{C}$ & \\
\hline \multicolumn{3}{|l|}{ 1-O-feruloyl } \\
\hline $1^{\prime}$ & $127.39, \mathrm{C}$ & \\
\hline $2^{\prime}$ & $111.51, \mathrm{CH}$ & $6.93(1 \mathrm{H}, \mathrm{d}, J=1.9)$ \\
\hline $3^{\prime}$ & $150.63, \mathrm{C}$ & \\
\hline $4^{\prime}$ & $149.19, \mathrm{C}$ & \\
\hline $5^{\prime}$ & $116.39, \mathrm{CH}$ & $6.57(1 \mathrm{H}, \mathrm{d}, J=8.2)$ \\
\hline $6^{\prime}$ & $123.79, \mathrm{CH}$ & $6.75(1 \mathrm{H}, \mathrm{dd}, J=8.2,1.9)$ \\
\hline $7^{\prime}$ & $147.45, \mathrm{CH}$ & $7.53(1 \mathrm{H}, \mathrm{d}, J=15.9)$ \\
\hline $8^{\prime}$ & $115.58, \mathrm{CH}$ & $6.26(1 \mathrm{H}, \mathrm{d}, J=15.9)$ \\
\hline $9^{\prime}$ & $168.74, \mathrm{C}$ & \\
\hline $3^{\prime}-\mathrm{OCH}_{3}$ & $56.18, \mathrm{CH}_{3}$ & $3.67(3 \mathrm{H}, \mathrm{s})$ \\
\hline \multicolumn{3}{|l|}{ 3-O-feruloyl } \\
\hline $1^{\prime \prime}$ & $127.43, \mathrm{C}$ & \\
\hline $2^{\prime \prime}$ & $111.57, \mathrm{CH}$ & $6.83(1 \mathrm{H}, \mathrm{d}, J=1.9)$ \\
\hline $3^{\prime \prime}$ & $150.35, \mathrm{C}$ & \\
\hline $4^{\prime \prime}$ & $149.02, \mathrm{C}$ & \\
\hline $5^{\prime \prime}$ & $116.28, \mathrm{CH}$ & $6.67(1 \mathrm{H}, \mathrm{d}, J=8.2)$ \\
\hline $6^{\prime \prime}$ & $124.13, \mathrm{CH}$ & $6.88(1 \mathrm{H}, \mathrm{dd}, J=8.2,1.9)$ \\
\hline $7^{\prime \prime}$ & $146.93, \mathrm{CH}$ & $7.54(1 \mathrm{H}, \mathrm{d}, J=15.9)$ \\
\hline $8^{\prime \prime}$ & $115.70, \mathrm{CH}$ & $6.16(1 \mathrm{H}, \mathrm{d}, J=15.9)$ \\
\hline $9^{\prime \prime}$ & $167.75, \mathrm{C}$ & \\
\hline $3^{\prime \prime}-\mathrm{OCH}_{3}$ & $56.08, \mathrm{CH}_{3}$ & $3.60(3 \mathrm{H}, \mathrm{s})$ \\
\hline
\end{tabular}

${ }^{1}$ Assigned by HMBC data.

Compound 2 was identified as $p$-hydroxybenzaldehyde based on the characteristic UV spectrum and $m / z$ value of $121[\mathrm{M}-\mathrm{H}]^{-}$in the negative ion detection mode along with NMR data (Supplementary Materials, Figure S4 and Table S1), whereas compound 3 was identified as $N$-trans-feruloyltyramine based on an interpretation of spectroscopic data, including NMR and MS spectra (Supplementary Materials, Figures S2 and S5, and Table S2) [25]. 
<smiles>COc1cc(/C=C/C(=O)OC2CC(O)C(OC(=O)/C=C/c3ccc(O)c(OC)c3)(C(C)=O)CC(O)C2O)ccc1O</smiles>

(1)<smiles>O=Cc1ccc(O)cc1</smiles><smiles>COc1cc(/C=C/C(=O)NCCc2ccc(O)cc2)ccc1O</smiles>

(3)

Figure 1. Chemical structures of compounds 1 to 3; (1) 1,3-di-O-trans-feruloyl-(-)-quinic acid, (2) p-hydroxybenzaldehyde, and (3) N-trans-feruloyltyramine.

\subsection{Quantitative Analysis of Compounds $\mathbf{1}$ to $\mathbf{3}$ in EA-a and MC-bg}

Quantitative analysis of the isolated compounds was accomplished based on absolute qHNMR using an internal calibrant. Recently, qHNMR has been established as a standard scientific method for determination of purity and for quantitative analysis applied to the International Conference on Harmonization (ICH) and the United States Pharmacopeia (USP). LC-ESI-MS data revealed that compound $\mathbf{1}$ was the major component of EA-a, and the weight percentage of $\mathbf{1}$ in EA-a was calculated using the qHNMR method (Supplementary Materials, Figure S6 and Table S6). Likewise, we calculated the weight percentages of compounds 2 and 3 in MC-bg (Supplementary Materials, Figure S7 and Table S7). Notably, we detected a slight change in the ${ }^{1} \mathrm{H}$ NMR chemical shifts of $\mathbf{1}$ in the extract, and the assignment of the ${ }^{1} \mathrm{H}$ NMR signal of compound $\mathbf{1}$ in EA-a was confirmed by performing a spiking experiment. The weight percentage of compound $\mathbf{1}$ in EA-a was calculated to be $4.64 \pm 0.26 \%$ (CV 0.06), whereas those of compounds 2 and 3 in MC-bg were calculated as $0.87 \pm 0.01 \%(\mathrm{CV} 0.01)$ and $4.61 \pm 0.03 \%$ (CV 0.01), respectively.

\subsection{Biological Activities of Compounds $\mathbf{1}$ to $\mathbf{3}$}

Compounds 1-3 were isolated as the major bioactive compounds in the fractions obtained and were evaluated in antioxidant assays (Figure 2). While compound $\mathbf{2}$ showed no antioxidant activity up to $500 \mu \mathrm{g} / \mathrm{mL}(4.1 \mathrm{mM})$, we found that compounds 1 and 3 scavenged both DPPH and ABTS radicals (Table 4). Compound 1, a major compound of EA-a, was found to scavenge DPPH and ABTS radicals with $\mathrm{IC}_{50}$ values of 17.50 and $30.06 \mu \mathrm{M}$, respectively. Similarly, compound 3 showed antioxidant activities against DPPH and ABTS with $\mathrm{IC}_{50}$ values of 14.90 and $26.14 \mu \mathrm{M}$, respectively (Supplementary Materials, Tables S3 and S4).

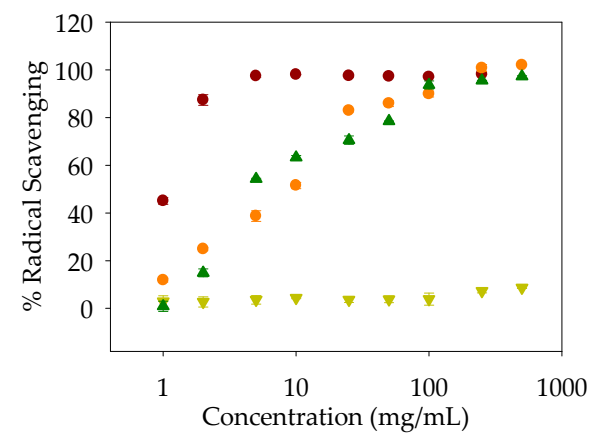

(a)

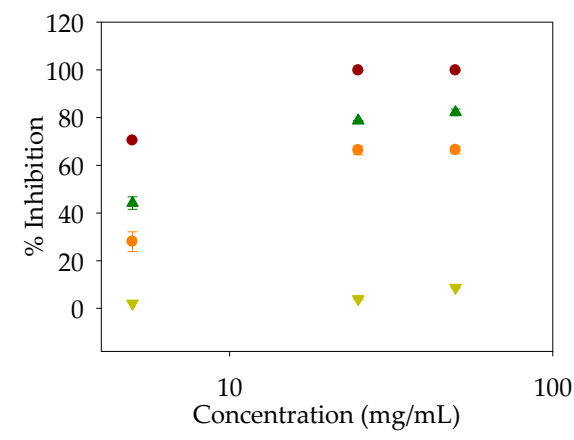

(b)

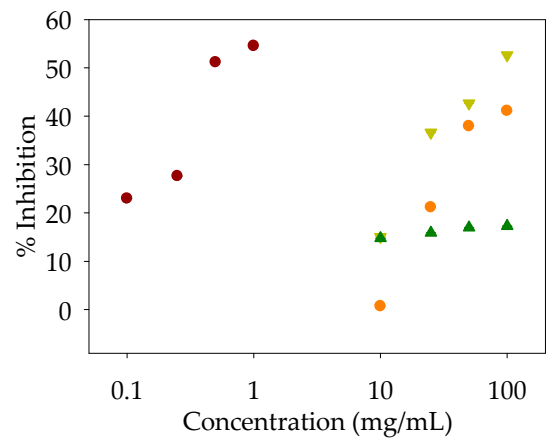

(c)

Figure 2. Dose-dependent activities of compounds $\mathbf{1}$ to $\mathbf{3}$ [control $(\bullet) ; \mathbf{1}(\bullet) ; \mathbf{2}(\nabla) ; \mathbf{3}(\mathbf{\Delta})$ ]: (a) DPPH radical-scavenging activity (control: L-ascorbic acid); (b) ABTS radical-scavenging activity (control: L-ascorbic acid); (c) Pancreatic lipase activity (control: orlistat). 
Table 4. Bioactivities of compounds 1 to 3.

\begin{tabular}{|c|c|c|c|}
\hline Sample & $\begin{array}{c}\text { Radical-Scavenging Activity } \\
\text { Against DPPH } \\
\mathrm{IC}_{50}, \mu \mathrm{g} / \mathrm{mL}(\mu \mathrm{M})\end{array}$ & $\begin{array}{c}\text { Radical Scavenging Activity } \\
\text { Against ABTS } \\
\mathrm{IC}_{50}, \mu \mathrm{g} / \mathrm{mL}(\mu \mathrm{M})\end{array}$ & $\begin{array}{l}\text { Inhibition of Pancreatic Lipase } \\
\qquad \mathrm{IC}_{50}, \mu \mathrm{g} / \mathrm{mL}(\mu \mathrm{M})\end{array}$ \\
\hline Control & $1.17(6.64)^{1}$ & $3.50(19.87)^{1}$ & $0.49(0.98)^{3}$ \\
\hline 1 & $9.53(17.50)$ & $16.37(30.06)$ & $131.72(241.91)$ \\
\hline 2 & -2 & -2 & $86.71(710.02)$ \\
\hline 3 & $4.67(14.90)$ & $8.19(26.14)$ & -2 \\
\hline
\end{tabular}

In addition to the aforementioned antioxidant activities, we observed that compounds 1 and $\mathbf{2}$ inhibited pancreatic lipase (Table 4), although the inhibitory activity tended to be relatively weak, with $\mathrm{IC}_{50}$ value of 131.72 and $86.71 \mu \mathrm{g} / \mathrm{mL}(241.91$ and $710.02 \mu \mathrm{M})$, respectively.

\section{Discussion}

In this study, we found that the extracts and fractions of S. anglica exhibited free radical scavenging, pancreatic lipase inhibitory, and tyrosinase inhibitory activities. Fraction EA-a showed the most potent free radical scavenging and pancreatic lipase inhibitory activities, while MC-bg possessed the most potent tyrosinase inhibitory activity.

Chemical investigation of the bioactive fractions led to the isolation and identification of major compounds, 1,3-di-O-trans-feruloyl-(-)-quinic acid (compound 1, 4.64\%) from EA-a, $p$-hydroxybenzaldehyde (compound 2, 0.87\%) from MC-bg, and N-transferuloyltyramine (compound 3, 4.61\%) from MC-bg. Compound 1 showed free radical (DPPH and ABTS) scavenging activity and moderately inhibited pancreatic lipase activity, compound 2 showed moderate pancreatic lipase inhibitory activity, and compound 3 showed DPPH and ABTS radical scavenging activities.

Although the antioxidant activities of compound 3 were higher than those of compound 1, we found that EA-a showed more potent antioxidant activity than MC-bg, indicating that unidentified minor components might have additive or synergistic effects on the antioxidant activity of EA-a. Notably, although compound $\mathbf{1}$ was identified as the major constituent of EA-a, we found that fraction EA-a showed a slightly more potent lipase inhibitory activity than compound $\mathbf{1}$, indicating that the lipase inhibitor activity of EA-a is not solely derived from compound $\mathbf{1}$.

Likewise, at $100 \mu \mathrm{g} / \mathrm{mL}$, fraction MC-bg and compound 2 showed pancreatic lipase inhibitory activities of $33.3 \%$ and $52.65 \%$, respectively (Supplementary Materials, Table S5). Thus, we speculate that in addition to compound 2, there are trace components or components contributing to the lipase inhibitory activity of MC-bg.

Compounds 1-3 have been shown to have an inhibitory effect on the enzyme tyrosinase. For example, compound $\mathbf{1}$ isolated from the pollen of Calendula officinalis can inhibit the activity of tyrosinase against monophenolase and diphenolase, with $\mathrm{IC}_{50}$ values of $44.6 \pm 1.5$ and $134.4 \pm 4.8 \mu \mathrm{g} / \mathrm{mL}$, respectively [26]. Compound 2 isolated from cumin, a food spice, is a non-competitive tyrosinase inhibitor with an $\mathrm{IC}_{50}$ of $820 \mu \mathrm{M}[27,28]$, whereas compound 3 at $100 \mu \mathrm{M}$ shows $49 \pm 4 \%$ inhibition of human melanocyte tyrosinase [29]. Furthermore, compound 3 isolated from a stem extract of Aurea helianthus can downregulate microphthalmia-associated transcription factor, tyrosinase, and tyrosinase-related proteins in the inhibition of melanogenesis [30].

The major compounds 1-3 derived from bioactive fractions of S. anglica in this study are reported herein for the first time from this plant, although they have previously been reported from other plants as tyrosinase inhibitors with skin-whitening potential. The antioxidant activities of sulfur-containing organic acids; amino acids such as proline and glycine betaine, polysaccharides; and algicidal flavonols isolated from extracts of S. anglica have also been reported $[17,18]$. However, to the best of our knowledge, the present study is the first to investigate the radical scavenging, tyrosinase inhibitory, and pancreatic lipase inhibitory activities of sub-fractions of S. anglica extracts. 
The biological activities and phytochemical composition of plants vary by cultivation region and period, harvesting time, and processing of plant materials [31,32]. Because our results were obtained using the biomass collected in 2016, further studies are needed to investigate the seasonal variation in biological activities and phytochemical composition of S. anglica.

Furthermore, there are several reports on the hormetic effects of phytochemicals and herbal medicines $[33,34]$. Therefore, the hormetic dose-response mechanisms of the extracts and phytochemicals of S. anglica and their indirect effects on in vitro/ in vivo bioactivities need to be studied for the industrial development of this plant.

\section{Conclusions}

The biological activities of the extracts and fractions of the invasive plant S. anglica were investigated. EtOH-a and EtOH-bg were found to possess radical (DPPH and ABTS) scavenging, tyrosinase inhibitory, and pancreatic lipase inhibitory activities. Among the sub-fractions, the EA-a fraction showed the most potent radical scavenging properties and pancreatic lipase inhibition. The major constituent of EA-a was identified as 1,3-di-O-trans-feruloyl quinic acid (1) with radical scavenging and pancreatic lipaseinhibiting properties. The MC-bg fraction was found to inhibit L-DOPA oxidation. The two major compounds of MC-bg were identified as $p$-hydroxybenzaldehyde (2), and $N$-trans-feruloyltyramine (3), which have been previously reported as tyrosinase inhibitors. Our results indicate that the extracts and fractions of the invasive plant S. anglica are potential sources of antioxidants and skin-whitening and anti-obesity agents that could have beneficial applications in the future development of biomedicines, health supplements, and cosmetics.

Supplementary Materials: The following data are available online at https:/ / www.mdpi.com/20 76-3921/10/2/242/s1, Figure S1: LC-ESI-MS data of EA-a; Figure S2: LC-ESI-MS data of MC-bg; Figure S3: 1D NMR spectra of compound 1 in $\mathrm{CD}_{3} \mathrm{OD}$; Figure S4: 1D NMR spectra of compound 2 in $\mathrm{CD}_{3} \mathrm{OD}$; Figure S5: 1D NMR spectra of compound 3 in $\mathrm{CD}_{3} \mathrm{OD}$; Figure S6: qHNMR spectra of compounds $\mathbf{1}$ in EA-a with an internal standard; Figure S7: qHNMR spectrum of compounds 2 and 3 in MC-bg with an internal standard; Table S1: NMR data of $p$-hydroxybenzaldehyde (2) in $\mathrm{CD}_{3} \mathrm{OD}$; Table S2: NMR data of $N$-trans-feruloyltyramine (3) in $\mathrm{CD}_{3} \mathrm{OD}$; Table S3: DPPH radical-scavenging activity of 1-3; Table S4: ABTS radical-scavenging activity of 1-3; Table S5: Pancreatic lipase inhibition by 1-3; Table S6: Spiked qHNMR data of compound 1 in EA-a; Table S7: qHNMR data of compounds 2 and 3 in MC-bg.

Author Contributions: G.J.K. prepared the manuscript and performed identification and quantification of purified compounds derived from bioactive fractions; S.P., E.K., and H.K. collected plant specimens and prepared extracts and fractions; H.-J.P. performed biological assays; J.-W.N. designed quantitative NMR experiments and analyzed the acquired data; S.-S.R. designed the biological assays and analyzed the activity data; and H.C. supervised the study. All authors have read and agreed to the published version of the manuscript.

Funding: This research was supported by a grant from the National Research Foundation of Korea (NRF-2020R1A6A1A03044512) and 2019 Yeungnam University Research Grants.

Institutional Review Board Statement: Not applicable.

Informed Consent Statement: Not applicable.

Data Availability Statement: Data is included within the article and the supplementary materials.

Conflicts of Interest: The authors declare no conflict of interest.

\section{References}

1. Hubbard, J.C.E. Spartina marshes in southern England. IV. Pattern of invasive in Poole Harbour. J. Ecol. 1965, 53, 799-813. [CrossRef]

2. Baumel, A.; Ainouche, M.L.; Misset, M.T.; Gourret, J.P.; Bayer, R. Genetic evidence for hybridization between the native Spartina maritima and the introduced Spartina alterniflora (Poaceae) in South-West France: Spartina x neyrautii re-examined. Plant Syst. Evol. 2003, 237, 87-97. [CrossRef] 
3. Millard, A.V.; Evans, P.R. Spartina Anglica in Great Britain. Focus on Nature Conservation, Liverpool University, United Kingdom, 10th November 1982; Doody, P., Ed.; Nature Conservancy Council: Cambridgeshire, UK, 1984; Volume 5, pp. 41-48.

4. Shimeta, J.; Saint, L.; Verspaandonk, E.R.; Nugegoda, D.; Howe, S. Long-term ecological consequences of herbicide treatment to control the invasive grass, Spartina anglica, in an Australian saltmarsh. Estuar. Coast. Shelf Sci. 2016, 176, 58-66. [CrossRef]

5. Otte, M.L.; Haarsma, M.S.; Broekman, R.A.; Rozema, J. Relation between heavy metal concentrations in salt marsh plants and soil. Environ. Pollut. 1993, 82, 13-22. [CrossRef]

6. Thompson, J.D. The Biology of an Invasive Plant: What makes Spartina anglica so successful? BioScience 1991, 41, 393-401. [CrossRef]

7. Strong, D.R.; Ayres, D.R. Ecological and evolutionary misadventures of Spartina. Annu. Rev. Ecol. Evol. Syst. 2013, 44, 389-410. [CrossRef]

8. Kim, E.K.; Kil, J.H.; Joo, Y.K.; Jung, Y.S. Distribution and botanical characteristics of unrecorded alien weed Spartina anglica in Korea. Weed Turfgrass Sci. 2015, 4, 65-70. [CrossRef]

9. Yang, S.; Lian, G. ROS and diseases: Role in metabolism and energy supply. Mol. Cell. Biochem. 2020, 467, 1-12. [CrossRef]

10. Baranowska, M.; Bartoszek, A. Antioxidant and antimicrobial properties of bioactive phytochemicals from cranberry. Postepy Hig. Med. Dosw. 2016, 70, 1460-1468. [CrossRef] [PubMed]

11. Yuan, Y.; Zhang, J.; Fan, J.; Clark, J.; Shen, P.; Li, Y.; Zhang, C. Microwave assisted extraction of phenolic compounds from four economic brown macroalgae species and evaluation of their antioxidant activities and inhibitory effects on $\alpha$-amylase, $\alpha$-glucosidase, pancreatic lipase and tyrosinase. Food Res. Int. 2018, 113, 288-297. [CrossRef] [PubMed]

12. Djaoudene, O.; López, V.; Cásedas, G.; Les, F.; Schisano, C.; Bachir Bey, M.; Tenore, G.C. Phoenix dactylifera L. seeds: A by-product as a source of bioactive compounds with antioxidant and enzyme inhibitory properties. Food Funct. 2019, 10, 4953-4965. [CrossRef]

13. Larher, F.; Hamelin, F.; Stewart, G.R. L'acide diméthylsulfonium-3 propanoïque de Spartina anglica. Phytochemistry 1977, 16, 2019-2020. [CrossRef]

14. van Diggelen, J.; Rozema, J.; Dickson, D.M.J.; Broekman, R. Beta-3-dimethylsulphoniopropionate, proline and quaternary ammoniumcompounds in Spartina anglica in relation to sodium chloride, nitrogen and sulfur. New Phytol. 1986, 103, 573-586. [CrossRef]

15. Grignon-Dubois, M.; Echmak, C. First evaluation of the marine invasive species Spartina anglica as a potential renewable source of glycine betaine. J. Appl. Pharm. Sci. 2013, 3, 29-34.

16. Li, Y.L.; Chen, J.H.; Song, X.K.; Sun, J.Y.; Zhan, Y.C. Optimization of microwave extraction of polysaccharides from Spartina anglica using RSM. Lishizhen Med. Mater. Med. Res. 2013, 24, 2126-2128.

17. Xu, N.J.; Tang, J.; Zhang, Z.W.; Yan, X.J. Inhibitory effects of Spartina anglica on Heterosigma akashiwo and Prorocenrum micans and the isolation and identification of the algicidal compounds. Chin. J. Appl. Ecol. 2009, 20, 2563-2568.

18. Sun, X.; Tang, J.; Hu, W.; Xu, N. Antioxidant flavonol compounds from the marine cordgrass Spartina anglica. Food Sci. Technol. Res. 2013, 19, 1093-1097. [CrossRef]

19. Park, C.H.; Tanaka, T.; Kim, H.Y. Protective effects of Corni Fructus against advanced glycation endoproducts and radical scavenging. Evid. Based Complementary Altern. Med. 2012, 2012, 418953. [CrossRef] [PubMed]

20. Re, R.; Pellegrini, N.; Proteggente, A. Antioxidant activity applying an improved ABTS radical cation decolorization assay. Free Radic. Biol. Med. 1999, 26, 1231-1237. [CrossRef]

21. Nerya, O.; Musa, R.; Khatib, S.; Tamir, S.; Vaya, J. Chalcones as potent tyrosinase inhibitors: The effect of hydroxyl positions and numbers. Phytochemistry 2004, 65, 1389-1395. [CrossRef]

22. Kim, J.H.; Kim, H.J.; Park, H.W.; Youn, S.H.; Choi, D.Y.; Shin, C.S. Development of inhibitors against lipase and $\alpha$-glucosidase from derivatives of monascus pigment. FEMS Microbiol. Lett. 2007, 276, 93-98. [CrossRef]

23. Folin, O.; Denis, W. On phosphotungtic-phosphomolybdic compounds as color reagents. J. Biol. Chem. 1912, 12, 239-243. [CrossRef]

24. Scholz-Böttcher, B.M.; Ernst, L.; Maier, H.G. New stereoisomers of quinic acid and their lactones. Liebigs Ann. Chem. 1991, 1991, 1029-1036. [CrossRef]

25. Hwang, J.T.; Kim, Y.; Jang, H.J.; Oh, H.M.; Lim, C.H.; Lee, S.W.; Rho, M.C. Study of the UV light conversion of feruloyl amides from Portulaca oleracea and their inhibitory effect on IL-6-induced STAT3 activation. Molecules 2016, 21, 865. [CrossRef] [PubMed]

26. Olennikov, D.N.; Kashchenko, N.I. 1,5-Di-O-isoferuloylquinic acid and other phenolic compounds from pollen of Calendula officinalis. Chem. Nat. Compd. 2014, 50, 589-593. [CrossRef]

27. Seo, S.Y.; Sharma, V.K.; Sharma, N. Mushroom tyrosinase: Recent prospects. J. Agric. Food Chem. 2003, 51, 2837-2853. [CrossRef] [PubMed]

28. Kubo, I.; Kinst-Hori, I. Tyrosinase inhibitors from cumin. J. Agric. Food Chem. 1998, 46, 5338-5341. [CrossRef]

29. Okombi, S.; Rival, D.; Bonnet, S.; Mariotte, A.M.; Perrier, E.; Boumendjel, A. Analogues of N-hydroxycinnamoylphenalkylamides as inhibitors of human melanocyte-tyrosinase. Bioorg. Med. Chem. Lett. 2006, 16, 2252-2255. [CrossRef]

30. Kim, Y.; Lee, S.; Ryu, J.H.; Yoon, K.D.; Shin, S.S. Effect of Aurea helianthus stem extract on anti-melanogenesis. Biosci. Biotech. Biochem. 2018, 82, 1871-1879. [CrossRef] [PubMed]

31. Adegbaju, O.D.; Otunola, G.A.; Afolayan, A.J. Effects of growth stage and seasons on the phytochemical content and antioxidant activities of crude extracts of Celosia argentea L. Heliyon 2020, 6, e04086. [CrossRef] [PubMed]

32. Wang, Y.-Z.; Li, P. Effect of cultivation years on saponins in Paris Polyphylla var. yunnanensis using ultra-high liquid chromatographytandem mass spectrometry and Fourier transform infrared spectroscopy. Plant. Growth Regul. 2018, 84, 373-381. [CrossRef] 
33. Wang, D.; Calabrese, E.J.; Lian, B.; Lin, Z.; Calabrese, V. Hormesis as a mechanistic approach to understanding herbal treatments in traditional Chinese medicine. Pharm. Ther. 2018, 184, 42-50. [CrossRef] [PubMed]

34. Franco, R.; Navarro, G.; Martínez-Pinilla, E. Hormetic and mitochondria-related mechanisms of antioxidant action of phytochemicals. Antioxidants 2019, 8, 373. [CrossRef] [PubMed] 